\section{JURNAL ABDIMAS

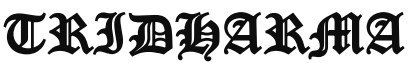

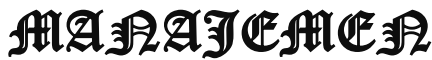

P-ISSN 2615-6849, E-ISSN 2622-3686

Jurnal ABDIMAS Vol. 2, No. 2, April 2021 Hal (47-53)

@ Prodi Manajemen Fakultas Ekonomi Universitas Pamulang

Email: abdimasjurnal.unpam@ gmail.com Telp: (021) 741-2566

\title{
PENGARUH IKLAN TV TERHADAP PENCITRAAN GAYA HIDUP PADA KARANG TARUNA KELURAHAN PAMULANG TIMUR
}

\author{
Nina Shabrina, RR. Mardiana Yulianti, Rahmayanti Tumanggor, \\ Achmad Yasin Fadli, Suroto
}

Dosen Ekonomi Fakultas Ekonomi Universitas Pamulang

Email : dosen01567@unpam.ac.id ,dosen00155@unpam.ac.id, dosen02223@unpam.ac.id, dosen00949@unpam.ac.id, dosen00488@unpam.ac.id

\begin{abstract}
ABSTRAK
Pengabdian Kepada Masyarakat (PKM) merupakan bagian integral dari Tri Dharma Perguruan Tinggi yang dalam pelaksanaannya tidak terlepas dari dua dharma yang lainnya, serta melibatkan segenap sivitas akademika: dosen, mahasiswa, tenaga kependidikan serta alumni. Melalui PKM sivitas akademik dapat hadir di tengahtengah masyarakat.

Teknologi dapat diartikan sebagai segala sesuatu yang digunakan untuk memudahkan suatu pekerjaan. Teknologi yang kita gunakan umumnya berupa kompoter, handphone, telephone, televise, radio, dan lain-lain. Teknologi memiliki keunggulan tersendiri pada setiap fungsinya. Misalnya televisi dapat membantu memudahkan kominikasi secara luas. Televisi digunakan untuk menyiarkan berita, pertandingan olah raga, kompetisi ajang pencarian bakat, reality show, sinetron, iklan, dan sebagainya.

Teknologi televisi yang digunakan untuk menyiarkan iklan memiliki keunggulan dalam promosi suatu merek produk karena dapat dilihat secara luas oleh pemirsa. Iklan adalah suatu bentuk komunikasi yang digunakan untuk menyampaikan suatu informasi tentang produk, layanan, ataupun informasi lainnya. Iklan televisi pada umumnya lebih mudah mempenggaruhi pemirsa karena setiap hari ditayangka, bahkan setiap acara televisi selalu disela dengan iklan. Dengan begitu suatu produk yang secara terus-menerus ditayangkan akan meninggalkan bekas pada ingatan pemirsa, sehingga mereka akan mulai terpengaruh dengan produk yang diiklankan.

Sebuah iklan produk akan memberikan citra yang selalu memikat orang yang melihatnya. Suatu merek produk akan menarik perhatian orang yang memperhatikan iklan. Pemirsa yang melihat kemudahan-kemudahan yang ditayangkan sebuah iklan, pada akhirnya tertarik untuk memiliki produk yang diiklankan dengan maksud agar dapat meringankan pekerjaannya. Dan pada akhirnya mereka mulai berminat untuk memiliki produk tersebut.
\end{abstract}

Kata Kunci: Iklan, televisi, gaya hidup

\section{ABSTRAC}

Community Service (PKM) is an integral part of the Tri Dharma of Higher Education which in its implementation is inseparable from the other two dharmas, and involves all academicians: lecturers, students, educational staff and alumni. Through PKM, the academic community can be present in the midst of society.

Technology can be defined as anything that is used to facilitate a job. The technology we use is generally in the form of computers, cellphones, telephones, televisions, radios, and others. Technology has its own advantages in each function. For example television 


\section{JURNAL ABDIMAS

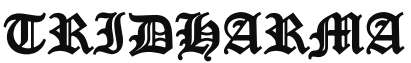 AtA}

P-ISSN 2615-6849, E-ISSN 2622-3686

Jurnal ABDIMAS Vol. 2, No. 2, April 2021 Hal (47-53)

@Prodi Manajemen Fakultas Ekonomi Universitas Pamulang

Email: abdimasjurnal.unpam @ gmail.com Telp: (021) 741-2566

can help facilitate widespread communication. Television is used to broadcast news, sports competitions, talent search competitions, reality shows, soap operas, advertisements, and so on.

Television technology used to broadcast advertisements has an advantage in the promotion of a product brand because it can be seen widely by viewers. Advertising is a form of communication that is used to convey information about products, services or other information. Television advertisements in general are easier to influence viewers because every day they are aired, even every television program is always interrupted by an advertisement. That way a product that is continuously aired will leave a mark on the memory of viewers, so they will start to be influenced by the product advertised.

A product advertisement will provide an image that will always captivate people who see it. A product brand will attract the attention of people who pay attention to the advertisement. Viewers who see the conveniences that an advertisement displays, are ultimately interested in having the advertised product with the intention of making their work easier. And in the end they began to be interested in owning the product.

\section{Keywords: Advertising, television, lifestyle}

\section{PENDAHULUAN}

Penyajian iklan televisi yang informatif dan persuasif serta dikemas secara menarik dengan menampilikan gambar yang spektakuler hasil perekayasaan gambar dengan sentuhan teknologi audio visual yang mevisualisasikan beragam cerita dibalik beraneka ragamnya kebutuhan hidup, mulai dari kalangan bawah sampai kalangan teratas, telah mengantar keinginan kita untuk memiliki dari produk yang ditawarkan tersebut. Berbagai macam produk kebutuhan, mulai dari kebutuhan primer demi kelangsungan hidup seharihari sampai dengan kebutuhan mewah demi naiknya identitas diri di mata masyarakat, telah membayang-bayangi dan mencuci otak kita, agar kita ikut larut di dalam buaian ceritanya dan berakhir dengan tindakan untuk membeli dari produk yang setiap detik dan menit itu, telah tertangkap oleh mata kita tatkala kita sedang menikmati program acara televisi dengan santainya.

Tiap hari dan tiap menit mata kita disuguhi oleh ratusan illustrasi terselip dalam kemasan produk yang diklankan lewat layar kaca dan tanpa sadar kita telah terbius oleh rayuan, bujukan serta tipuan yang menggoda pikiran kita untuk membelinya.

Iklan televisi sebagai salah satu bagain yang tak terpisahkan dari rangkaian tayangan program acara televisi, di mana kemunculannya selalu menghiasi dalam hitungan menit di sela-sela ketika kita sedang menyaksikan Sinetron "Si Markonah Penyambung Lidah Wanita", di salah satu sudut ruangan tamu di mana televisi bertengger di depan sofa.

Televisi telah menjadi bagian penting dari suatu kehidupan masyarakat modern yang berfungsi selain sebagai penyebar informasi dan hiburan, juga sebagai suatu alat promosi produk paling ampuh dalam menggiring pikiran masyarakat yang menjadi target audiensnya. Kita tanpa sadar telah diperdaya oleh keberadaan iklan televisi untuk masuk dalam jebakannya, melalui rangkaian gambar yang menarik hingga pada akhirnya nanti kita terprovokasi olehnya dan rela merogoh kantong, hanya untuk mengikuti tawaran melalui citraan gambar yang fantastik itu.

Derasnya intensitas Iklan televisi yang dilancarkan melalui media layar kaca itu, telah sedikit banyak mempengaruhi para pemirsa untuk mengikuti jejak dari illustarsi yang telah mengopsesi para pemirsa lewat citraan produknya itu, demi 


\section{JURNAL ABDIMAS

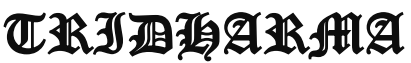

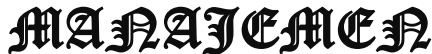

P-ISSN 2615-6849, E-ISSN 2622-3686

Jurnal ABDIMAS Vol. 2, No. 2, April 2021 Hal (47-53)

@ Prodi Manajemen Fakultas Ekonomi Universitas Pamulang

Email: abdimasjurnal.unpam @ gmail.com Telp: (021) 741-2566 mendapatkan tuntutan "gaya hidup" yang notabene bagian penting dari kehidupan masyarakat modern. Dewasa ini fenomena gaya hidup masyarakat modern dengan keragaman kompleksitas problema yang ada, telah terserap oleh sebagian besar masyarakat, hal ini dapat terjadi tidak lain dan tidak bukan dari pengaruh tayangan televisi yang dilihatnya. Gejala ini dalam perkembangannya, begitu pesat masuk dalam relung-relung kehidupan dari semua lapisan masyarakat, keberadaannya tumbuh subur di masyarakat perkotaan bahkan hingga kini telah mengepedemi sampai tingkat pedesaan, menyerang siapa saja yang menjadi targetnya, tak peduli anakanak, kaum remaja bahkan orang tuapun terseret dan telah menjadi mangsa dari proses modernisasi gaya hidup.

Derasnya durasi penayangan iklan televisi dari berbagai macam merek produk, ditengah selipan acara-acara di televisi yang kita tonton setiap hari, telah berdampak pada meningkatnya gaya hidup masyarakat dan bercermin pada citraan iklan televisi. Segala macam apa yang dicitrakan oleh beragam produk konsumtif lewat iklan televisi, akan ditiru oleh masyarakat dan dianggap sebagai alat untuk peningkatan kualitas identitas diri, dalam kehidupan masyarakat modern yang semakin lama cenderung menuju ke arah kehidupan glamour dalam masyarakat kapitalis dan hanyalah melahirkan manusiamanusia konsumtif dan hedonis. Lihat saja cerminan realitas kehidupan remaja dewasa ini, seringnya di kalangan remaja, gonta ganti assesoris mulai dari kemasan handphone, gelang, kalung, cincin ,minuman kaleng, tas, sepatu sampai pakaian ala artis idolanya serta rambut dengan warna warni bagaikan toko cat mowilex berjalan, setiap saat berseliweran di tengah kehidupan kita.

Penggambaran tentang penganalogian dampak yang ditimbulkan oleh iklan televisi tidak berhenti di situ saja, para anak-anak sekolah dasarpun ikut bergaya memakai Handphone yang tergolong mahal harganya. Fenomena ini akan mengejutkan lagi ketika sikap para orang tua merasa gatal terbius oleh kegombalan iklan televisi dan ikut-ikutan mempercantik dirinya, ia tak mau kalah dengan anak gadisnya dengan memotong rambutnya gaya seorang artis idolanya menjadi bergelombang bagai rangkaian serutan kayu jati yang melambai-lambai tertiup angin mamiri. Begitu dasyatnya pengaruh iklan televisi terhadap pencitraan gaya hidup seseorang, hingga sampaisampai orang mau mengeluarkan segala macam kemampuan, meskipun dalam perjanannya diwarnai dengan susah payah untuk meraihnya, demi untuk mengikuti trend gaya hidup yang sudah menjadi bagian penting dalam masyarakat modern.

Fenomena diatas menjadi bahan pertimbangan bagi pemerintah dalam membuat kebijakan pendidikan dan pengawasan orangtua dalam mendidik putra putri yang berusia remaja. Sehingga pengenalan perkembangan teknologi dan pemahaman mendalam pada penggunaan televisi dan smartphone digunakan untuk hal positif dan bermanfaat. Berdasarkan permasalahan tingkat penggunaan gadget yang tinggi dan kekhawatiran akan perilaku mengikuti iklan untuk gaya hidup pada kalangan remaja , maka pengabdian kepada masyarakat (PKM) ini mengambil Tema "Pengaruh Iklan TV terhadap pencitraan gaya hidup pada Karang Taruna Kelurahan Pamulang Timur".

\section{RUMUSAN MASALAH} adalah :

Rumusan masalah pada PKM ini

1. Bagaimana mengenalkan pengetahuan bahaya perilaku iklan kepada karang taruna Kelurahan Pamulang Timur?

2. Bagaimana agar karang taruna Kelurahan Pamulang Timur bisa memiliki pengetahuan menganalisa pengaruh teknologi terhadap gaya hidup?

\section{TUJUAN PELAKSANAAN}

Tujuan umum dari kegiatan pengabdian kepada masyarakat ini adalah: 


\section{JURNAL ABDIMAS

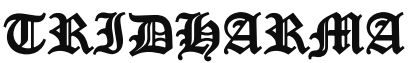

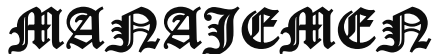

P-ISSN 2615-6849, E-ISSN 2622-3686

Jurnal ABDIMAS Vol. 2, No. 2, April 2021 Hal (47-53)

@ Prodi Manajemen Fakultas Ekonomi Universitas Pamulang

Email: abdimasjurnal.unpam @ gmail.com Telp: (021) 741-2566
1. Memberikan informasi terkait pengetahuan pola sikap dan perilaku dalam menganalisis iklan tv terhdap kebutuhan yang sesuai kepada karang taruna Kelurahan Pamulang Timur.

2. Memberikan informasi tentang penggunaan teknologi untuk kreativitas dan pendampingan orangtua di kalangan karang taruna Kelurahan Pamulang Timur.

\section{TINJAUAN PUSTAKA}

Iklan atau advertising dapat difinisikan sebagai "any paid form of nonpersonal communication about an organization, product, service, or idea by an identified sponso" (setiap bentuk komunikasi nonpersonal mengenai sutau organisasi, produk, servis, atau ide yang dibayar oleh satu sponsor yang diketahui).

Adapun maksud 'dibayar' pada definisi tersebut menunjukkan fakta bahwa ruang dan waktu bagi suatu pesan iklan pada umumnya harus dibeli. Maksud kata 'nonpersonal' berarti suatu iklan melibatkan media massa (televisi, radio, majalah, koran) yang dapat mengirimkan pesan kepada sejumlah besar kelompok individu pada saat bersamaan. Dengan demikian sifat nonersonal iklan berarti pada umumnya tidak tersedia kesempatan untuk mendapatkan umpan balik yang segera dari penerima pesan.

Iklan merupakan salah satu bentuk promosi yang paling dikenal dan paling banyak dibahas orang. Hal ini kemungkinana karena daya jangkauannya yang luas. Iklan juga menjadi instrument promosi yang sangat penting khususnya bagi perusahaan yang memproduksi barang atau jasa yang ditujukan kepada masyarakat luas.

Iklan televisi pada umumnya terdiri atas iklan sponsorship, iklan layanan masyarakat, iklan spot, promo ad, dan iklan politik. Iklan televisi berkembang dengan berbagai kategori di samping karena iklan televisi perlu kreativitas dan menghasilkan produk-produk iklan baru, namun juga karena daya beli masyarakat terhadap sebuah iklan televisi selalu bervariasi karena tekanan ekonomi. Namun bila kita bandingkan dengan media lain, iklan televisi memiliki kategorisasi yang jauh berbeda karena sifat media yang juga berbeda. Kategori besar dari sebuah iklan televisi adalah berdasarkan sifat media ini, di mana iklan televisi dibangun dari kekuatan visualisasi objek dan kekuatan audio. Siimbol-simbol yang divisualisasi lebih menonjol bila dibadingkan dengan symbol-simbol verbal. Umumnya iklan televisi menggunakan cerita-cerita pendek, maka iklan televisi berupaya keras meninggalkan kesan yang mendalam pemirsa dalam waktu beberapa detik.

Suatu perilku masyarakat tehadap sebuah iklan yang ditayangkan televisi dapat dipengaruhi oleh beberapa factor. Konsumen tidak membuat keputusan pembelian pada suatu lingkungan yang terisolasi. Konsumen berada di tengah masyarakat dan berinteraksi dengan masyarakat tempat ia berada. Dalam hal ini terdapat factor eksternal yang diketahui memberi pengaruh pada proses pengambilan keputusan

\section{METODE PELAKSANAAN}

Persoalan yang dihadapi oleh karang taruna Kelurahan Pamulang Timur adalah banyak remaja yang masih belum memahami bahayanya pengaruh iklan yang berlebihan dan belum mengerti bagaimana kebutuhan mendasar pada usia remaja. Adapun permasalahan tersebut dapat dicarikan solusinya sebagai berikut ini: Berdasarkan uraian masalah yang dihadapi oleh mitra, maka disepakati bahwa masalah utama yang dihadapi oleh mitra adalah siswa masih belum begitu memahami tentang bahayanya pengaruh iklan dan pentingnya menganalisis bahaya dan manfaat iklan untuk kebutuhan sehari sehari yang sesuai dengan perilaku, usia dan budaya Indonesia. Untuk mencapai keberhasilan pengabdian, maka diperlukan 


\section{JURNAL ABDIMAS

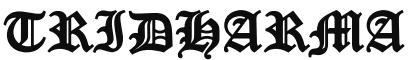

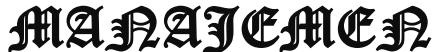

P-ISSN 2615-6849, E-ISSN 2622-3686

Jurnal ABDIMAS Vol. 2, No. 2, April 2021 Hal (47-53)

@ Prodi Manajemen Fakultas Ekonomi Universitas Pamulang

Email: abdimasjurnal.unpam @ gmail.com Telp: (021) 741-2566 partisipasi yang baik oleh mitra. Bentuk partisipasi mitra antara lain:

a. Mendukung secara penuh kegiatan pengabdian.

b. Memberikan data terkait dengan hambatan yang dihadapi untuk mengurangi penggunaan televisi dan gadget.

c. Memberikan masukan tentang bagaimana menjadi seorang remaja produktif.

d. Mempelajari dan mengaplikasikan materi-materi yang telah diberikan.

e. Berkoordinasi secara aktif selama kegiatan pengabdian.

Sebagai upaya untuk menilai apakah penyuluhan yang dilakukan telah diaplikasikan atau belum oleh mitra dan sejauh mana pelatihan dapat berpengaruh terhadap perkembangan dalam menulis proposal kegiatan dan surat menyurat maka perlu dilakukan evaluasi. Evaluasi dilakukan dengan mendatangi guru dan menanyakan apakah siswa memahami betul tentang entrepreneur dan leadership.

\subsection{Realisasi Pemecahan Masalah}

Berdasarkan permasalahan utama mitra yang telah dijelaskan pada poin sebelumnya, maka solusi permasalahan yang di tawarkan kepada mitra adalah:

1. Sebagai upaya menyelesaikan permasalahan utama yang dihadapi oleh mitra yaitu siswa yang belum memahami tentang bagaimana menjadi perilaku yang baik dalam kegiatan penggunaan teknologi sesuai kebutuhan. Maka solusi yang kami tawarkan adalah dengan memberikan pendampingan dan penyuluhan tentang bagaimana membangun jiwa qonaah dan bersyukur dengan apa yang dimiliki.

2. Sebagai upaya menyelesaikan permasalahan kedua yaitu tentang membentuk jiwa kreativitas, maka kami menawarkan beberapa cara terkait dengan upaya agar mereka termotivasi memiliki jiwa kreatif.
Semua solusi yang kami tawarkan akan dapat tercapai bilamana terjalin komunikasi yang baik antara penyelenggara kegiatan PKM dalam hal ini civitas akademika di Program Studi Manajemen dan mitra yaitu karang taruna Kelurahan Pamulang Timur saling bekerjasama untuk mewujudkan kesuksesan acara tersebut.

Dalam upaya mencari solusi atas permasalahan yang dihadapi oleh mitra, maka kami menawarkan target solusi dalam penyelesaian sesuai dengan target yang sudah kami siapkan dan kami sepakati dengan pihak mitra. Adapun solusi tersebut akan kami laporkan dalam bentuk luaran kegiatan PKM yang terdiri dari beberapa tahapan:

a. Luaran PKM terkait bagaimana menjadi remaja yang berkepribadian baik dan berperilaku produktif.

b. Luaran PKM terkait upaya memiliki jiwa kreatif.

\subsection{Khalayak Sasaran}

Khalayak sasaran dalam kegiatan pengabdian pada masyarakat ini adalah karang taruna Kelurahan Pamulang Timur.

\subsection{Tempat dan Waktu}

Kegiatan Pengabdian pada masyarakat ini dilaksanakan pada tanggal 04 Maret - 06 Maret 2021.

\section{HASIL DAN PEMBAHASAN}

Pengaruh Iklan Televisi terhadap Masyarakat dapat dilihat pada penggunaan masyarakat akan teknologi., maka suatu masyarakat harus memiliki system teknologi yang baik (Denis Goulet). Dengan demikian maka fungsi teknologi adalah kunci utama perubahan di masyarakat. Teknologi secara fungsional telah menguasai masyarakat, bahkan pada fungsi yang substansial,seperti mengatur beberapa system norma di masyarakat.

Pada iklan lain, sabun "Surf" umpamanya atau sabun "Rinso". Gambaran 


\section{JURNAL ABDIMAS

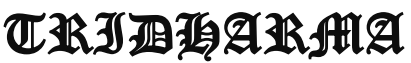

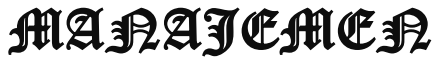

P-ISSN 2615-6849, E-ISSN 2622-3686

Jurnal ABDIMAS Vol. 2, No. 2, April 2021 Hal (47-53)

@ Prodi Manajemen Fakultas Ekonomi Universitas Pamulang

Email: abdimasjurnal.unpam @ gmail.com Telp: (021) 741-2566 mengenai kemudahan dan kekuatan produk deterjen itu dalam iklan, tidak selamanya dapat dibuktikan dalam dunia nyata. Pengetahuan itu hanyalah realitas yang dibangun oleh iklan televisi dalam media televisi untuk menjelaskan betapa hebatnya sebuah produk, sehingga pemirsa sampai kepada kesimpulan mengenai produ tersebut akan memudahkan pekerjaannya.

Selain menawarkan dunia instan, iklan terutama iklan televisi merupakam pertunjukan 'kecil' dalam dunia komunikasi dengan kesan-kesan yang 'besar' sebagai suatu system magis (the magic system). Sebagai the magic system, iklan dapat mengubah nasib seseorang dalam satu malam. Pak Ahmad seorang guru SD berubah nasibnya dalam semalam, mendadak kayak karena makan mie instan bermerek 'Indomie', atau dengan menabung sepuluh ribu rupiah di Bank BCA. Magic, itulah kata yang sering disebut masyarakat untuk menggambarkan betapa iklan mempertontonkan sebuah dunia kognitif kepada pemirsanya. Iklan bahkan mamapu mereproduksi anganangan kehidupan manusia tentang kehidupan mewah dalam keajaiban seribu satu malam.Dalam hal tertentu individu bebas merespon iklan yang ditayangkan, sejauh itu pula individu terikat dengan sisitem yang ada. Oleh karena itu sistemikut mempengaruhi respon individu. System yang dimaksud adalah system dominan seperti seperti lingkungan kerja dan kekuasaan, system subordinasi, dan sistem radikal. Sistem-sistem tersebut menjadi bagian penting da menentukan strategi meraih target dalam satu tayangan iklan

Banyaknya pengusaha yang menjual produk yang sama, menuntut pengusaha untuk terus melakukan inovasi agar dapat bertahan dalam persaingan. Demi memenangkan persaingan, pengusaha melakukan berbagai strategi untuk mengenalkan produknya serta meningkatkan penjualannya. Salah satu strategi perusahaan yaitu melalui promosi Media televisi dianggap paling efektif dibandingkan media yang lain. Hal tersebut dikarenakan melalui televisi, orang dapat melihat gambar dan suara yang disajikan oleh pengiklan, sedangkan media cetak hanya dapat melihat gambar tanpa mendengan pesan yang disampaikan, demikian pula dengan iklan radio yang hanya dapat mendengar pesan suara tetapi tidak dapat melihat bentuk produk.

Tujuan mengiklankan sebuah Sikap sebagai suatu evaluasi yang menyeluruh terhadap suatu produk dengan menilai produk tersebut menguntungkan atau tidak menguntungkan. Konsumen akan melakukan keputusan pembelian setelah menentukan sikap terhadap suatu produk. Sikap yang positif terhadap suatu produk akan membawa konsumen untuk membeli produk tersebut, tetapi sebaliknya sikap yang negatif akan menghalangi konsumen untuk membeli produk tersebut. Oleh karena itu, sikap konsumen perlu diketahui oleh pengusaha agar dapat mendorong konsumen untuk melakukan pembelian terhadap produk yang ditawarkannya Media televisi dianggap paling efektif dibandingkan media yang lain. Hal tersebut dikarenakan melalui televisi, orang dapat melihat gambar dan suara yang disajikan oleh pengiklan, sedangkan media cetak hanya dapat melihat gambar tanpa mendengan pesan yang disampaikan, demikian pula dengan iklan radio yang hanya dapat mendengar pesan suara tetapi tidak dapat melihat bentuk produk

\section{DAFTAR PUSTAKA}

A. A Mangkunegara, Manajemen Sumber Daya Manusia, Bandung, Resdakarya, 2007)

A. Usmara, Motivasi Kerja, Yogyakarta, Asmara Book, 2006

Alam S, Jakarta: Esis, 2007

Buchari Alma, (1999). Kewirausahaan, Bandung, Alfabeta 


\section{JURNAL ABDIMAS

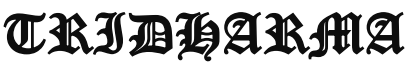

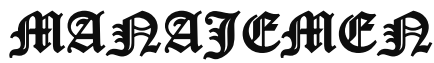

P-ISSN 2615-6849, E-ISSN 2622-3686

Jurnal ABDIMAS Vol. 2, No. 2, April 2021 Hal (47-53)

@ Prodi Manajemen Fakultas Ekonomi Universitas Pamulang

Email: abdimasjurnal.unpam@gmail.com Telp: (021) 741-2566
Bari'ah, dkk, Hubungan antara Kualitas Layanan Bank dengan Minat Menabung Nasabah PT BRI Kantor Cabang Ungaran, Semarang, Universitas Diponegoro

Depdikbud, Kamus Besar Bahasa Indonesia, edisi ketiga, Jakarta, Balai Pustaka, 2002

Depdiknas, Undang-Undang Sistem Pendidikan Nasional, Jakarta, Depdiknas,

Pasaribu, V. L. D., Susanti, F., \& Hartuti, E. T. K. (2019). Memotivasi Siswa dan Siswi SMK Letris Indonesia di Dalam Menentukan Pilihan Untuk Melanjutkan Pendidikan Atau Bekerja Setelah Lulus Sekolah. Jurnal Pengabdian Dharma Laksana, 1(2), 161-172.

Pasaribu, V. L. D., Agrasadya, A., Shabrina, N., \& Krisnaldy, K. (2020). MENJADI ENTERPRENEUR MUDA YANG MEMILIKI JIWA LEADERSHIP UNTUK MENGHADAPI MASA DEPAN. Abdi Laksana, 1(1).

Pasaribu, V. L. D., Elburdah, R. P., Sudarso, E., \& Fauziah, G. (2020). PENGGUNAAN MANAJEMEN WAKTU TERHADAP PENINGKATAN PRESTASI BELAJAR DI SMP ARAISIYAH. Jurnal ABDIMAS Tri Dharma Manajemen, l(1).

Pasaribu, V. L. D., Sulaiman, S., Sutiman, S., Thaharudin, T., \& Purnomo, B. Y. (2020). PENGENALAN LETAK POSYANDU

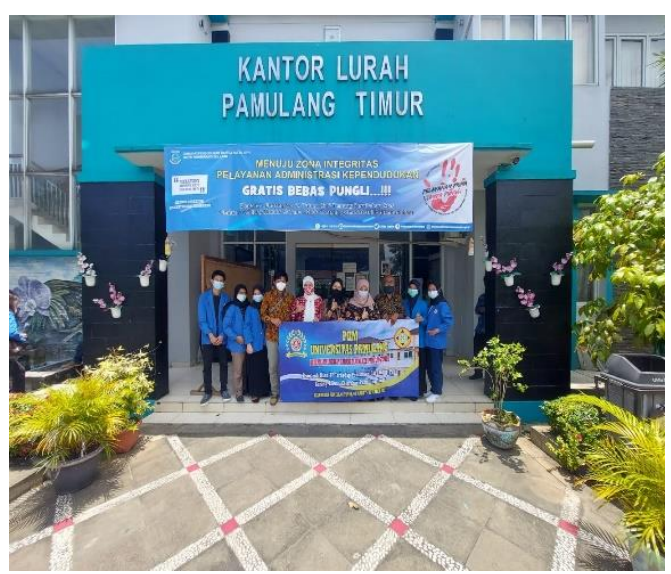

TERDEKAT DIKELURAHAN PISANGAN DENGAN MANAJEMEN PEMASARAN REVOLUSI 4.0 UNTUK MENINGKATKAN PENGETAHUAN MASYARAKAT LETAK DAN FUNGSI POSYANDU TERDEKAT PADA KELURAHAN PISANGAN. DEDIKASI PKM, I(1), 105-110.

Pasaribu, V. L. D., Oktrima, B., Prabowo, B., Arianto, N., \& Haryoko, U. B. (2020). PROGAM PENDAMPINGAN DAN PENYELENGGARAAN PENDIDIKAN ANAK PADA USIA DINI TERHADAP PRESTASI BELAJAR DILINGKUNGAN RT 020 RW 009. KEL GIRI PENI. KEC WATES. YOGYAKARTA. JURNAL LOKABMAS KREATIF, 1(1), 71-75.

\section{DOKUMENTASI FOTO KEGIATAN}

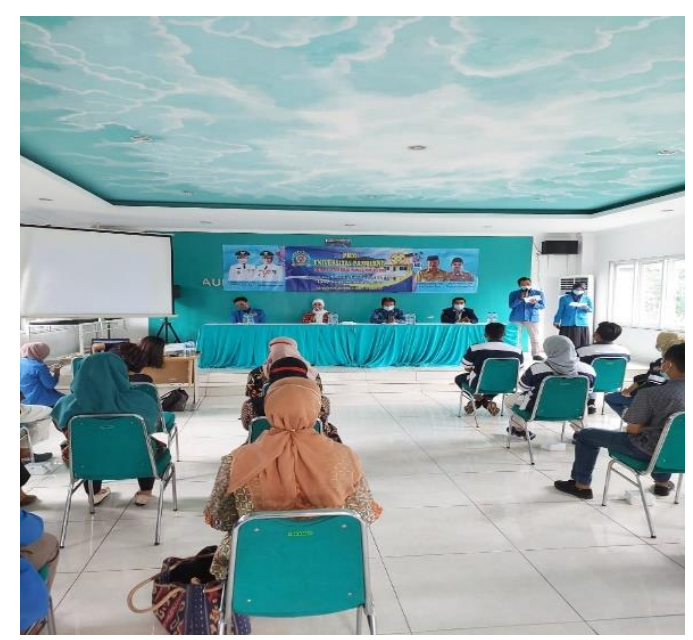

